\title{
YNARI E O PODER EVOCATIVO DAS PALAVRAS: A GUERRA CIVIL EM ANGOLA NO CONTO DE ONDJAKI
}

\author{
Pietro Gabriel dos Santos Pacheco ${ }^{1}$
}

\begin{abstract}
Resumo: Ambientado num contexto de guerra civil pós-independência angolana, o presente trabalho tem por objetivo a análise do conto Ynari: a menina de cinco tranças, do escritor Ondjaki. Com bastante desenvoltura, somos colocados diante de uma narrativa simples, mas grandiosa em seu conteúdo. Ynari, nossa protagonista, é uma menina que gostava de passear perto de sua aldeia, ouvir os pássaros e sentar-se na margem do rio. Certo dia, em uma dessas andanças, encontrou um pequeno homem saído do capim. O elemento fabular aqui se encontra presente e nos leva a vermos a guerra pelo controle da nação renascida pelos olhos de uma criança. Para teorizar serão abordadas as teorias de Bruno Bettelheim, Robert Darnton e Elias Canetti.
\end{abstract}

Palavras-chave: conto fabular; literatura angolana; guerra civil;

\section{A estrutura do conto}

Vês? Às Vezes uma coisa pode ser tão grande (ONDJAKI).

Desde o princípio, o homem sempre procurou explicações para os fenômenos compreensíveis e incompreensíveis. Uma vez entendidos, precisavam ser transmitidos. Nascia assim o conto. Manifestado, primeiramente de forma oral, era ele o responsável por perpetuar o entendimento e o ensinamento entre o povo que estava inserido. Antes de entrar na análise do conto, é necessário levantar alguns aspectos presentes na obra: o primeiro deles é o tom fabular que aproxima a narrativa daquelas escritas entre os séculos XVIII e XIX, por Charles Perrault, os irmãos Grimm, ou mesmo Hans Christian Andersen. Contendo uma narrativa curta, diferente do romance, apresenta certa linearidade e unidade estrutural. Para acontecer, é necessário se construir uma história focada em um conflito básico e apresentar, ao longo de seu desenvolvimento, a resolução do mesmo problema. Não obstante, ele deve ter um tom moralizante e instrutivo. Além de estar enraizado na cultura daqueles que o transmitem.

Visões de mundo não podem ser descritas da mesma maneira que acontecimentos políticos, mas não são menos reais [...]. O próprio senso

\footnotetext{
${ }^{1}$ Mestrando em Teoria da Literatura pela Pontifícia Universidade Católica do Rio Grande do Sul. Especializado em Literatura Brasileira pela PUCRS. Graduado em Licenciatura Plena no curso de História pela PUCRS.
}

Revista de Letras JUÇARA, Caxias - Maranhão, v. 03, n. 01, p. 7 - 17, ago. $2019 \mid 7$ 
comum é uma elaboração social da realidade [...]. Longe de ser a invenção arbitrária de uma imaginação coletiva, expressa a base comum de uma determinada ordem social².

Com a finalidade de conscientizar e explicar sobre os acontecimentos comuns à determinada sociedade, o conto Ynari: a menina de cinco tranças, do escritor Ondjaki, nos convida para presenciarmos os últimos dias da Guerra Civil Pós-Independência (1975-2002), em Angola, entre o Movimento Popular para Libertação de Angola (MPLA) ${ }^{3}$ e a União Nacional para a Independência Total de Angola (UNITA ${ }^{4}$ a partir dos olhos de uma criança. Os horrores da guerra são apontados de maneira delicada e inteligente, por meio da adição de elementos fantásticos e morais, sem romper com a visão de mundo político e social, realocados como elementos secundários, face ao poder da palavra. $O$ conto não se refere ao acontecimento histórico e não procura trazer em sua gênese a fidelidade do fato, porém é impossível negar traços cotidianos de quem o relata.

A cultura é uma das chaves de leitura para a compreensão das ações das personagens que atuam de maneira coletiva, e fazem com que aqueles que leem sobre ela, sintam-se identificados. O "Era uma vez" introdutório nos chama para entrar em um mundo infantil e mágico, onde o humor, a moral e criaturas folclóricas dialogam com personagens de carne e osso. Neste caso, um homem muito pequenino e sua aldeia com dois sábios anciãos: um velho capaz de criar palavras, e uma velha com poder de destruí-las. Três elementos principais que evidenciam o público destinatário do relato "para todas as crianças de Angola e do mundo".

A presença destas personagens estrutura o conto como fabular. Fábula, em uma breve explicação, é a narrativa em prosa curta, ou poema breve de caráter

\footnotetext{
2 DARNTON, Robert. O grande massacre de gatos: e outros episódios da história cultural francesa. Tradução de Sônia Coutinho. São Paulo: Graal, 2001, p. 38/9.

${ }^{3}$ Surgido em meados da década de 1960, o MPLA foi um grupo de origem marxista que lutou pela independência de Angola do jugo português. Atualmente, é um partido político e vem desde 1975 comandando o país (SCHUBERT, Joe. 2013. Democratização e consolidação do poder político em Angola no pós-guerra. Disponível em:http://www.scielo.mec.pt/pdf/ri/n37/n37a07.pdf. Acesso em: 03 de junho de 2018).b

${ }^{4}$ Surgido também na década de 1960, a União Nacional para a Independência Total de Angola forma a oposição do MPLA. É considerado um grupo considerado <rebelde > por assumir um caráter mais violento e controlador (SCHUBERT, Joe. 2013. Democratização e consolidação do poder político em Angola no pós-guerra. Disponível em:http://www.scielo.mec.pt/pdf/ri/n37/n37a07.pdf. Acesso em: 03 de junho de 2018).
} 
moralizante. Aqui, nada é representado realisticamente, mas sim de modo figurado, estabelecendo sempre uma conexão com a situação social e a condição servil das protagonistas. Buscando dialogar com a teoria proposta por Bruno Bettelheim, na obra A Psicanálise dos contos de fadas (1973), podemos dividir estórias deste gênero em quatro momentos distintos e interligados (p. 36):

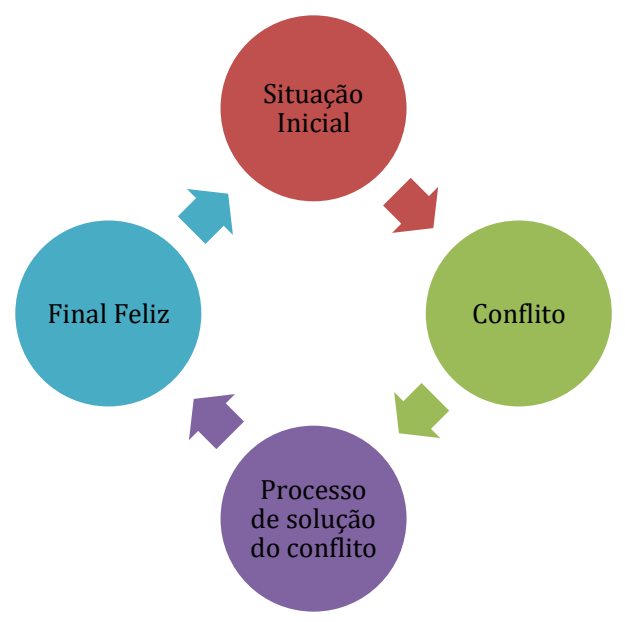

Ynari, protagonista que dá nome ao título, é uma menina que gostava de passear perto da sua aldeia, ouvir os pássaros, sentar-se na margem do rio. Certo dia, em uma de suas andanças, encontra um homem muito pequenino, saído do capim. Esta personagem mudará a sua história para sempre.

A "situação inicial" nos mostra o contexto em que as personas do conto estão inseridas. É nesta etapa que conhecemos algumas características sobre aqueles que irão conduzir a narrativa. No segundo momento, denominado "conflito", temos a apresentação de um problema que tira os protagonistas de seus status quo, levando-os ao processo seguinte que se constitui como o processo de solução do conflito e este, conduzindo-nos, finalmente, ao final feliz. Vale ressaltar que, por ter um caráter fabular, a narrativa apresenta uma moral. Para Antônio Cândido (1995), essas criações ficcionais ou poéticas são:

[...] mola da literatura em todos os seus níveis e modalidades, está presente em cada um de nós, analfabeto ou erudito - como anedota, causo, história em quadrinhos, noticiário policial, canção popular, moda de viola, samba carnavalesco. [...] a literatura concebida no sentido mais 
amplo a que me referi parece corresponder a uma necessidade universal, que precisa ser satisfeita e cuja satisfação constitui um direito $[\ldots]^{5}$.

Transportando o sentido trazido por Cândido para o caso de Ondjaki, o fator principal não busca responder tanto à necessidade universal, e sim, construir a partir do trauma vivenciado por angolanos em guerra civil, possibilidades de mudança. A identificação inicial com a situação apresentada leva à moralização das consequências da guerra e o quanto a paz está ao alcance de todos, principalmente das crianças, o futuro de Angola. Não trabalhamos com o conceito de uma doutrinação, porém, de uma conscientização de que a violência não é a única solução.

\section{As fases do conto}

A Revolução dos Cravos marcou o fim do regime ditatorial ${ }^{6}$ que perdurou até após a morte do ditador António Salazar, com Marcelo Caetano. Este segundo, porém, com uma visão menos impositiva, o que possibilitou que as lutas no território colonial pendessem para o lado angolano. A Revolução dos Cravos, oriunda dos pensamentos difundidos entre os portugueses, colocou fim, de maneira pacífica, ao golpe que persistia por quase 41 anos. E isso refletiu em território africano.

Diferente da democratização sem violência da Metrópole, em Angola e demais territórios o sangue persistiu sendo derramado. O ponto principal para isso está na distribuição territorial dos habitantes que sempre foi uma questão administrativa difícil. Tanto pela sua composição étnica que englobava algumas

5 CANDIDO, Antônio. O Direito à Literatura. In: Vários Escritos. 3ee. São Paulo: Duas Cidades, 1995., p. 176-177.

${ }^{6}$ A ditadura é instaurada em Portugal na sequência do golpe do 28 de maio de 1926, que derruba a I República (1910-1926). Assumindo, na primeira fase, uma feição militar (Ditadura Militar 19261933), a ditadura é constitucionalizada em 1933, autodenominando-se de Estado Novo. Um período definido como estado forte e interventor onde, apesar dos equilíbrios constitucionais, se assiste a uma ampla concentração de poderes na figura do professor de economia e então Presidente do Conselho, Antônio de Oliveira Salazar, e ao desenvolvimento de um amplo aparelho repressivo e propagandístico. Em setembro de 1968, na sequência de um acidente que o incapacita para continuar a exercer funções governativas, Oliveira Salazar é substituído por Marcelo Caetano que enceta uma fracassada tentativa de "liberalização" do regime (REZOLA, Maria Inácia. Do romantismo revolucionário à política real: a Revolução Portuguesa de 1974-1975. In GONÇALVES, Leandro Pereira; PAREDES, Marçal de Menezes. Depois dos Cravos: Liberdades e independências. Porto Alegre: EDIPUCRS, 2017). 
tribos dentro de um mesmo espaço, quanto pelos fluxos migratórios que compõem a história angolana.

Numa breve recapitulação do processo que desencadeou a libertação de Angola temos a partir dessa pluralidade o surgimento de grupos nacionalistas que, em nome de uma ideal mobilização anticolonial, irão plantar ideias populistas para e por angolanos. Esse sentimento é iniciado ainda na primeira metade do século XX por dois grupos de estudantes da elite que começam a se organizar e arquitetar os mecanismos para a independência territorial.

Surgem dessas reuniões dois grandes grupos: o MPLA (Movimento Popular para a Libertação de Angola) e a UNITA (União nacional para a Independência Total de Angola) que passam a combater a ameaça portuguesa, cada qual com seus métodos de guerrilha, porém contendo, em ambos os casos, um mesmo ideal. Entretanto, essa noção de nacionalidade não ocorria de maneira consciente e outros fatores pesavam para a adesão a esses grupos, por parte da população inculta, como vemos abaixo:

A maioria decidia o seu apoio com base em quem melhor poderia providenciar alimentos e bens, a favor de quem ocupasse a área onde viviam durante a independência, ou de quem demonstrasse maior capacidade de gerir a administração ${ }^{7}$.

Ter um representante nativo no poder era mais positivo do que permanecer subjugado pela mão dos portugueses que tomaram as terras e as riquezas que por direito eram dos primeiros habitantes, estes agora reduzidos a um trabalho quase escravo e subalterno. Era necessário que houvesse a formação de um grupo capaz de conter a ameaça lusitana, porém devido à distribuição mal elaborada do território pelos colonizadores, a tarefa tornava-se um tanto complicada. Com a saída dos portugueses do território e a independência de Angola vem a luta pela hegemonia territorial, uma disputa armada entre os principais grupos de resistência. E é sobre isto que o conto se desenrola.

7 PEARCE, Justin. A guerra nas cidades. In A guerra civil em Angola 1975-2002. Lisboa: Tinta da China, 2017, p. 189-215.

Revista de Letras JUÇARA, Caxias - Maranhão, v. 03, n. 01, p. 7 - 17, ago. $2019 \mid 11$ 
Sabendo deste contexto, somos apresentados à Ynari, menina que possui cinco tranças e que, em uma de suas caminhadas, conhece um pequeno homem e um reino desconhecido. Após o primeiro contato, combinam de se encontrar no dia seguinte. Na manhã do reencontro, homens começam a disparar uns contra outros e isso assusta Ynari que, rapidamente, é consolada pelo nosso pequenino homem. A frase "Não tenhas medo"8, resulta na ação do ser fantástico que transforma as armas em munições de barro. $O$ feito é observado com espanto, mas certo encanto. Como convite, a menina é convidada para conhecer o reino de seu amigo. Sempre margeando pelo rio do norte, dentro da floresta, entre duas árvores, temos o portão de sua tribo.

Para Hans Jellouschek (1975) a floresta é o espaço do inconsciente. Em muitos contos, tudo se origina nela, seja a iniciação do protagonista, ou o processo de sua identificação. Ela representa a escuridão que habita no homem e, somente após o mergulho nesse ambiente, que ele se torna um agente de transformação. Transferindo esse conceito para o conto, é nela que Ynari vai conhecer um casal de anciãos: um responsável por criar palavras e outra capaz de destruir toda e qualquer palavra na terra. É neste momento que a protagonista descobre a mágica verdadeira.

Sobre esses personagens, Ana Cláudia da Sila ${ }^{9}$ diz: "a ausência de uma liderança politicamente estruturada nos leva a pensar em uma organização anárquica". Apesar da desestrutura do território angolano, aquela pequena tribo escolheu duas figuras para manter a ordem. A idade avançada de ambos vinha com uma responsabilidade: carregar a tradição. Os contos só encontram validação em sociedades que se enxergam nele, logo, um cerimonial ritualístico vai preparar Ynari para o seu chamado.

Então os velhos deitaram ervas na cabeça e falaram a Ynari: Não temos uma magia para te dar, tens de ser tu a descobrir a tua própria magia. Hoje, querermos oferecer-te uma palavra e dar-te uma fórmula. Leva contigo a palavra 'permuta' e a fórmula, descobre-a dentro do teu coração $^{10}$.

\footnotetext{
8 ONDJAKI, Ndalu de Almeida. Ynari: a menina de cinco tranças. Conto. São Paulo: Companhia das Letras, 2014, p. 14.

9 SILVA, Ana Cláudia da. A Resistência da poesia angolana na Literatura InfantoJuvenil de Ondjaki, Volume 1, Número 1. Anais do CENA Uberlândia: EDUFU, 2013, p. 329.

10 ONDJAKI, Ndalu de Almeida. Ynari: a menina de cinco tranças. Conto. São Paulo: Companhia das Letras, 2014, p. 15.
} 
Todos somos mágicos! Era preciso que a menina descobrisse a sua magia e usasse-a para acabar com o sofrimento que os anos de Guerra tinham causado para seu povo - tanto entre angolanos e portugueses que se estendeu até a independência, quanto aquela que era sua contemporânea, entre angolanos pelo poder. Permuta! A palavra recebida era essa. Sem entender, guardou para si. $\mathrm{Na}$ noite, sonhou com um velho que explicou seu significado. Ao acordar, contou sobre o ocorrido ao pequeno amigo. Ela finalmente descobriu a sua mágica e precisava do homenzinho para acompanhá-la nesta breve aventura pelas cinco aldeias angolanas. Processo de solução do conflito.

Em nome da paz, era preciso que a palavra viesse junto com a ação. O fim da guerra dependia dela, não apenas da palavra entregue pelo velho, mas sim de Ynari como um todo. Ao passar por cada uma das cinco tribos, deixa uma de suas tranças. Permuta! A troca de algo seu para um bem maior. De maneira criativa, Ondjaki nos captura e nos leva a questionar sobre a importância do indivíduo enquanto cidadão e pertencente de uma população. Abrir mão de suas tranças, de sua característica feminina, quase como uma mártir: o preço necessário. A palavra necessitava de ação e era isso que ela estava destinada a fazer. Cada uma de suas tranças era uma parte de si que estava sendo deixada. Ela não era mais Ynari e sim, esperança:

\begin{abstract}
Ynari passou por todas as cinco aldeias, que andavam em guerra, pois numa não conseguiam ouvir, noutra não falavam, na terceira não viam, na quarta não cheiravam e na última não sentiam o sabor, curando todas com uma magia em que ela cortava uma trança e em troca as pessoas dessas aldeias ficavam curadas - uma permuta, acabando, assim, com a guerra $^{11}$.
\end{abstract}

Da palavra, a ação. E, como consequência, uma reação. Mais do que lei física, aqui, era necessário que ela deixasse aquilo que a caracterizava por um bem maior. Não por acaso que suas tranças simbolizavam cada uma das cinco tribos pertencentes ao território angolano. Em um pensamento antropológico, pode-se dizer que a fábula é um convite para a conscientização e o engajamento por parte das crianças, como se, assim como Ynari, elas também fossem parte de Angola.

11 ONDJAKI, Ndalu de Almeida. Ynari: a menina de cinco tranças. Conto. São Paulo: Companhia das Letras, 2014, p. 16.

Revista de Letras JUÇARA, Caxias - Maranhão, v. 03, n. 01, p. 7 - 17, ago. 2019| 13 
É interessante observar que, em cada uma das aldeias, a guerra deixara seu rastro. Em uma, o barulho dos disparos tirou a capacidade dos habitantes de ouvir as outras vozes; o estrondo das bombas era maior do que os próprios pensamentos dos habitantes daquele espaço. Em outra, a repressão fora tão violenta que impossibilitou que seus moradores pudessem falar, ou se expressar. $\mathrm{Na}$ terceira, não enxergavam. Metaforicamente, pode-se dizer que essa falta de visão está associada à oportunidade de fazer enxergar uma solução para os seus conflitos. Na quarta, a poeira e o resquício das bombas tiraram a condição de sentir outras sensações. E na quinta, o gosto da guerra era tão amargo que limitava seus cidadãos de experimentar outros sentimentos.

A metáfora da civilização moderna e de seu caos, defendida por Canetti e o ofício de autor, enquanto responsável pela sua organização, em outras palavras, "para dizer algo sobre este mundo que tenha algum valor, o poeta ${ }^{12}$ não pode afastá-lo de si ou evitá-lo. Tem que carregá-lo enquanto caos (2016, p. 318). De maneira fabular, e pelo olhar de uma criança, o escritor nos ambienta em um cenário de conflito que durava décadas e causava destruição e divisões na Angola renascida e construída por angolanos. A guerra dos adultos só poderia ser finalizada com uma nova geração, e é para estas que Ondjaki dedica este conto.

É para as crianças que ele entrega a esperança, o poder de transformação. É a partir delas que ele deposita a confiança. A paz só pode ser alcançada, ou conseguida quando houver uma identidade firmada dentro de si. Os anos coloniais e as guerras civis que se sucedem, até o momento de publicação do conto, podem encontrar o seu fim, no futuro, com a conscientização de uma geração que crescia.

Com o fim do conflito, passamos para o final feliz, a quarta e última etapa a ser analisada. Como um ciclo, a estória encerra-se e vai se encaminhando para o desfecho. A expressão que durante anos fez parte da história de Angola, agora já não serve mais. Como última missão, cabia ao pequeno homem levar à velha muito velhinha, a palavra 'guerra' para ser destruída. Com a paz instaurada e o novo tempo prometido, mas não cumprido por aqueles que disputavam o controle,

12 Sobre o uso da palavra 'poeta' (Dichter) em lugar de 'escritor' (Schrifsteller), Canetti optou pela primeira, pois não apenas abarca o fazer escrito, mas o cargo de sonhador (N. T) Introdução do livro A Consciência das palavras (CANETTI, Elias. A consciência das palavras. São Paulo: Companhia de Bolso, 2011, p. 12).

Revista de Letras JUÇARA, Caxias - Maranhão, v. 03, n. 01, p. 7 - 17, ago. 2019|14 
outra palavra nascia: despedida! O propósito foi cumprido e cabia a ambos seguirem seus rumos. O fim leva nossas personagens para onde tudo começou.

É no local onde se conheceram que eles se despedem. Cada um seguindo o seu caminho, com a sua mágica. Porém, a despedida não viria sozinha, ela traria outra palavra que consolaria ambos nos momentos de saudade: amizade. Maior de todas as dádivas. Enquanto ela existisse, um teria o outro para sempre. 0 sentimento improvável toma forma: "Desde a primeira vez que te vi senti uma coisa no meu coração, tão grande..." (p. 16). Brincando com os sentidos da vida e da paz, Ynari redescobre uma palavra antiga cheia de nova magia: Amizade!

O peso desta palavra era maior do que todo e qualquer sentimento. A menina apegada ao pequenino deseja rever o amigo; e o questiona sobre o próximo encontro. Como resposta, era preciso apenas que ela apanhasse uma boleia do humbi-humbi - pássaro bastante comum em território africano. Seguindo a lógica, seria impossível um ser tão pequeno comportar o peso de Ynari, mas é aí que o fantástico acontece: o peso não importa, pois, o coração da ave conseguia suportar o tamanho da menina. A mágica presente na narrativa encontra-se localizada no órgão que traz vida: o coração. Responsável por bombear o corpo, a sede dos sentimentos e, é através deles que a magia acontecesse.

A moral da história é tão simples, mas muito significativa: assim como Ynari, precisamos descobrir a nossa magia. Não importa qual seja o nosso tamanho, as palavras e ações que usarmos tem o poder de transformação. Mantendo a estrutura do conto fabular, a última frase do autor remete à tradição oral e a força de reprodução: "e como dizem os mais velhos, foi assim que aconteceu"13.

Ao estudar o conto de Ynari, podemos perceber elementos pertinentes e pertencentes de uma cultura. A estrutura, tal como aquela usada pelos escritores europeus, não se limita ao território destinado. Numa viagem de sensibilidade e sabedoria, onde é possível inventar ou destruir palavras, a estória transcende e encontra aceitação e identificação por parte de todos aqueles que ousam, assim como a protagonista de Ondjaki, mudar a sua realidade.

13 ONDJAKI, Ndalu de Almeida. Ynari: a menina de cinco tranças. Conto. São Paulo: Companhia das Letras, 2014, p. 16.

Revista de Letras JUÇARA, Caxias - Maranhão, v. 03, n. 01, p. 7 - 17, ago. 2019| 15 


\title{
YNARI AND THE EVOCATIVE POWER OF THE WORDS: THE CIVIL WAR IN ANGOLA ON THE TALE OF ONDJAKI
}

\begin{abstract}
In a context of post-independence Angolan civil war, the present work is based on the tale Ynari: a girl of five braids, by the writer Ondjaki. Quite easily, we are on the side of a simple but grand narrative in its content. Ynari, our protagonist, is a girl who likes to walk around her village, listen to the birds and sit on the bank of the river. One day, in one of those wanderings, I found a little man out of the grass. The fabled element here meets presents and the leads to see a war for the control of the nation reborn by the eyes of a child. The theories were approached as theories of Bruno Bettelheim, Robert Darnton and Elias Canetti.
\end{abstract}

Keywords: fairytale; angolan literature; civil war.

\section{Referências}

BETTELHEIM, Bruno. A psicanálise dos contos de fadas. Rio de Janeiro: Paz e Terra, 1978.

CANDIDO, Antônio. O Direito à Literatura. In: . Vários Escritos. 3ㄹed. São Paulo: Duas Cidades, 1995.

CANETTI, Elias. A consciência das palavras. São Paulo: Companhia de Bolso, 2011.

DARNTON, Robert. O grande massacre de gatos: e outros episódios da história cultural francesa. São Paulo: Graal, 2011.

ONDJAKI, Ndalu de Almeida. Ynari: a menina de cinco tranças. Conto. São Paulo: Companhia das Letras, 2014.

MENEZES, Solival. Mamma Angola: Sociedade e Economia de um País Nascente. São Paulo: Edusp, 2000.

PEARCE, Justin. A guerra nas cidades. In A guerra civil em Angola 1975-2002. Lisboa: Tinta da China, 2017, p. 189-215.

REZOLA, Maria Inácia. Do romantismo revolucionário à política real: a Revolução Portuguesa de 1974-1975. In GONÇALVES, Leandro Pereira; PAREDES, Marçal de Menezes. Depois dos Cravos: Liberdades e independências. Porto Alegre: EDIPUCRS, 2017.

RIBEIRO, Antônio Souza; RIBEIRO, Margarita Calafate. Geometrias da Memória: Configurações Pós-coloniais.InRIBEIRO, Antônio Souza; RIBEIRO, Margarita Calafate (orgs.). Geometrias da Memória: Configurações Pós-coloniais. Porto: Afrontamento, 2016. 
SCHUBERT, Joe. 2013. Democratização e consolidação do poder político em Angola no pós-guerra. Disponível em: $<$ http://www.scielo.mec.pt/pdf/ri/n37/n37a07.pdf>. Acesso em: 03 de junho de 2018.

SECCO, Lincoln. Trinta anos da Revolução dos Cravos in Revista Adusp, 33 ed. São Paulo: USP. Outubro de 2004.

SILVA, Ana Cláudia da. A Resistência da poesia angolana na Literatura InfantoJuvenil de Ondjaki, Volume 1, Número 1. Anais do CENA Uberlândia: EDUFU, 2013, p. 329.

Data da Submissão:18/01/2019

Data da Aprovação: 19/06/2019 